\title{
Notes on the vocalizations of Black-capped Sparrow (Arremon abeillei)
}

\section{Peter Boesman}

In the following we briefly analyze and compare voice of the two races of Black-capped Sparrow (Arremon abeillei). We also try to quantify the extent of any vocal differences using the criteria proposed by Tobias et al. (2010), as a support for taxonomic review.

We have made use of sound recordings available on-line from Xeno Canto (XC).

A comparison of song, illustrated with sonograms:

Song of A.a. abeillei

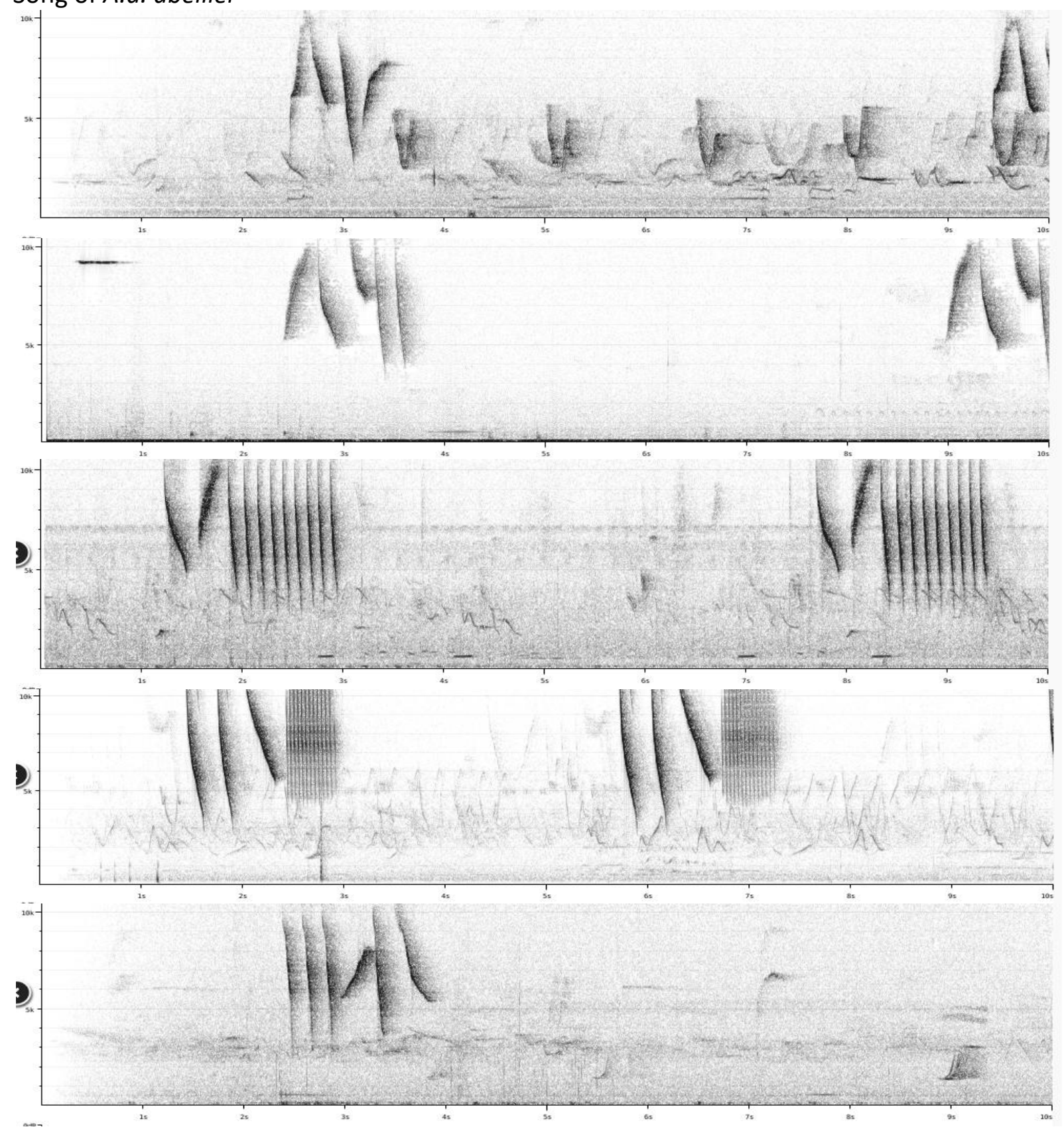


HANDBOOK OF THE

BIRDPFIUE WORLD ORNITHOLOGICAL NOTES

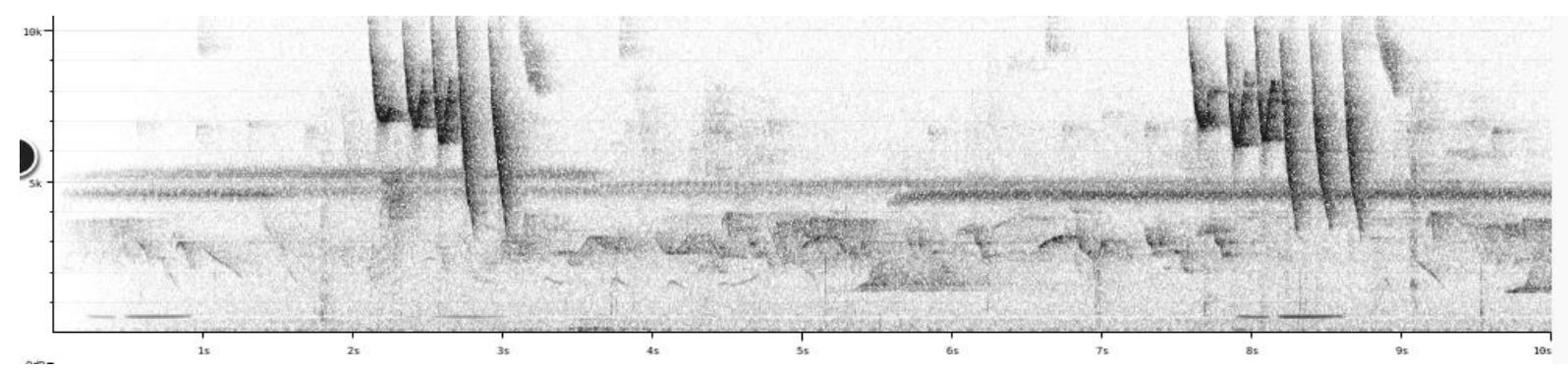

\section{Song of $A$.a. nigriceps}
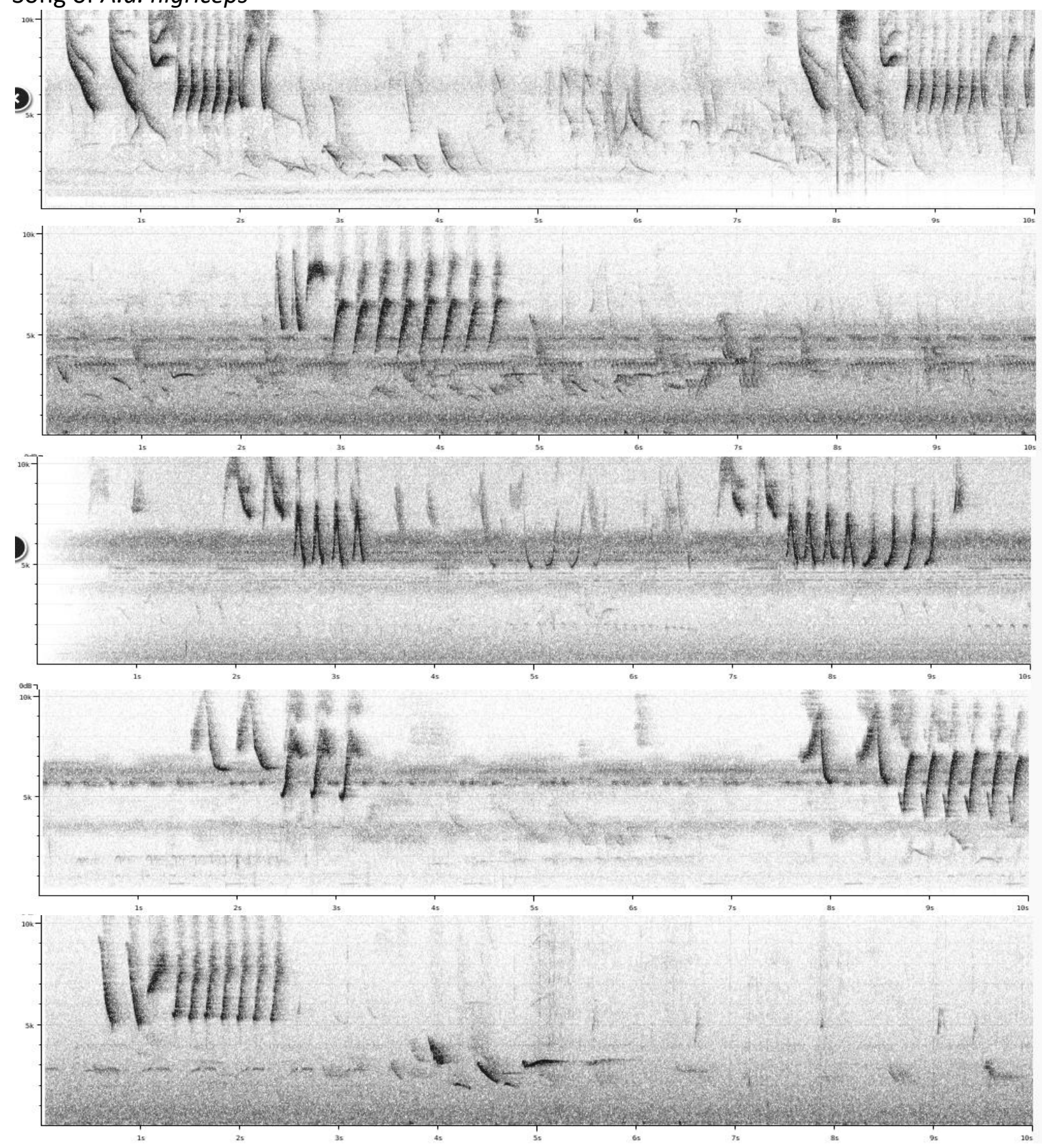

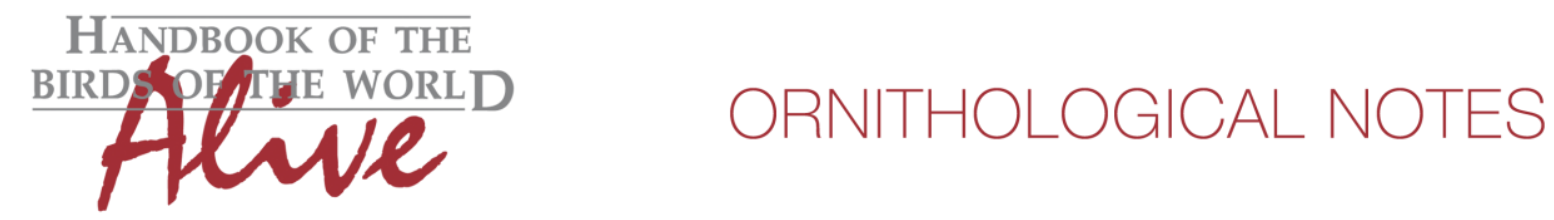

In both races, song consists of two parts:

part 1 is a sequence of 2-4 notes, often alternating rising and falling but sometimes just all identical notes.

part 2 (only in a few cases not present) is a more rapid series of repeated identical notes

There is quite some variability in song, and differences between the two races are rather subtle, but they can be safely told apart because of part 2:

abeillei has notes in part 2 which are sharply decreasing in pitch and which cover a large frequency range (bandwidth c. $5-7 \mathrm{kHz}$ ).

nigriceps has notes in part 2 which are rising in pitch (or occasionally sharply overslurred) and which have a smaller frequency range (c. $2-4 \mathrm{kHz})$.

The difference in frequency range of part 2 (over $5000 \mathrm{~Hz}$ for abeillei vs around $3000 \mathrm{~Hz}$ for nigriceps) leads to a score of 2-3, with notes rising in nigriceps (1-2). Another difference seems to be that the total length of the (full) song is on average shorter in abeillei (less than $2 \mathrm{~s} v s$ over $2 \mathrm{~s}$ for nigriceps (due to the repeated notes of part 2 delivered slower and/or more numerous).

This note was finalized on 4th January 2016, using sound recordings available on-line at that moment. We would like to thank in particular the sound recordists who placed their recordings for this species on XC: Roger Ahlman, Paul Coopmans, Ross Gallardy, Niels Krabbe, Frank Lambert, Mitch Leisinger, Huw Lloyd, Hans Matheve, John V Moore, Jonas Nilsson, Leonardo Ordoñez-Delgado, Fabrice Schmitt, Andrew Spencer, Charlie Vogt

\section{References}

Tobias, J.A., Seddon, N., Spottiswoode, C.N., Pilgrim, J.D., Fishpool, L.D.C. \& Collar, N.J. (2010). Quantitative criteria for species delimitation. Ibis 152(4): 724-746.

\section{Recommended citation}

Boesman, P. (2016). Notes on the vocalizations of Black-capped Sparrow (Arremon abeillei). HBW Alive Ornithological Note 362. In: Handbook of the Birds of the World Alive. Lynx Edicions, Barcelona. (retrieved from http://www.hbw.com/node/1252906 on 1 November 2016). 